\title{
Planos de ensino do Curso de Biblioteconomia da Universidade Federal do Rio Grande do Sul: estudo bibliométrico de referências
}

\author{
Educational plans for the Library Science Course taught \\ at the Universidade Federal do Rio Grande do Sul: \\ a bibliometric study of references
}

Sônia Domingues Santos BRAMBILLA ${ }^{1}$

Ida Regina Chittó STUMPF²

\begin{abstract}
RESUM O
O estudo reflete sobre a estrutura e organização dos planos de ensino do currículo do curso de graduação em Biblioteconomia da Universidade Federal do Rio Grande do Sul, no primeiro semestre de 2004. O objetivo principal foi traçar o perfil das referências dos planos de ensino, através da análise da tipologia dos documentos, idiomas referenciados, procedência dos autores, autores citados, auto-referenciação, temporalidade, periódicos referenciados, distribuição por disciplina, disponibilidade e acessibilidade dos documentos. Os procedimentos metodológicos utilizaram análise de referências na realização de um estudo bibliométrico. A revisão da literatura lançou um olhar sobre a Biblioteconomia no Brasil e fundamentos educacionais. Os resultados revelaram que livro e capítulo de livro perfazem $60 \%$ das citações, formato predominante dos documentos impresso, com $79 \%$. A análise da autoria expôs $60 \%$ de autores brasileiros, a Universidade Federal de Minas Gerais como instituição mais produtiva e a preferência pela autoria pessoal. A temporalidade apontou $70 \%$ das referências com data superior a 1990, o idioma mais citado foi o português e $80 \%$ de disponibilidade e acesso dos documentos. Pretendeu-se contribuir para a identidade e o auto-conhecimento do curso de Biblioteconomia da Universidade Federal do Rio Grande do Sul.
\end{abstract}

Palavras-chave: biblioteconomia; planos de ensino; bibliometria; análise de referências.

\section{A B STR A C T}

The study concerns the educational plan structure and organization of the "Universidade Federal do Rio Grande do Sul" Library Science program, in the 1st semester of 2004. Its main objective was to describe references cited in the educational plans by means of an analysis of document type, language, author origin, cited authors, self-cited author, publication year, journal title, distribution by discipline and document availability, and accessibility. The methodological procedures have employed techniques for analysis of references in a bibliometric study. The literature review addressed Library Science in Brazil and educational foundations. The main results revealed that book and book chapter make up $60 \%$ of the total number of citations, which is the

\footnotetext{
' Mestranda, Programa de Pós-Graduação em Comunicação e Informação, Faculdade de Biblioteconomia e Comunicação, Universidade Federal do Rio Grande do Sul. Porto Alegre, RS, Brasil.

2 Pesquisadora CNPq. Professora Doutora, Departamento de Ciência da Informação e do Programa de Pós-Graduação em Comunicação e Informação, Faculdade de Biblioteconomia e Comunicação, Universidade Federal do Rio Grande do Sul. Rua Ramiro Barcelos, 2705, $2^{\circ}$ andar, Santana, 90035-007, Porto Alegre, RS, Brasil. Correspondência para/Correspondence to: I.G.S. STUMPF. E-mail: <irstumpf@ufrgs.br>.
}

Recebido em 7/6/2005 e aceito para publicação em 23/9/2005. 
predominant format for printed documents, with $79 \%$. The authorship analysis revealed $60 \%$ of Brazilian authors, the "Universidade Federal de Minas Gerais" as the most productive institution, and a preference for personal authorship. The publication year pointed $70 \%$ of the references dated after 1990 . The most cited language was Portuguese and the availability and accessibility was above $80 \%$. The study was intended to contribute for the Course identity and self knowledge of the 'Universidade Federal do Rio Grande do Sul' Library Science Program.

Key words: library science; educational plans; bibliometric study; analysis of references.

\section{N T R O D U Ç Ã O}

A atual Sociedade da Informação exige um perfil renovado para o bibliotecário desenvolver e assumir suas atividades profissionais, na qual os saberes antigos devem ser reformulados e acrescidos do conhecimento em tecnologias, acompanhado de uma visão gerencial que permita administrar unidades de informação mais complexas. Aceitar essas responsabilidades é um desafio e deve nortear a educação básica, continuada e o aprimoramento pessoal do bibliotecário, que passa a ser visto como um profissional diferenciado da Informação. Para esta formação é preciso uma educação de qualidade, que incorpore nos programas dos cursos análises contextuais da Ciência da Informação, que possibilite vivência em pesquisa, desenvolvimento de consciência crítica e não se restrinja ao mero consumo e reprodução de informações.

Para os cursos de formação superior, o currículo é o documento maior, onde as disciplinas devem ser encaradas como partes de um todo, e interconectadas para permitir que se cumpram os objetivos da preparação profissional. A adequação e atualização das disciplinas podem ser verificadas através da análise dos seus planos de ensino. Uma das formas de análise é através da adequação, atualização e relevância das referências indicadas pelos professores.

O professor, ao indicar uma referência num plano de ensino, tem como objetivo tanto a formação básica quanto a construção continuada do conhecimento. Embora durante as práticas pedagógicas o docente não utilize todas as obras indicadas nos planos, oferece um rico referencial ao aluno, num documento que pode ser consultado durante todo o processo educacional e mesmo depois dele. Investigar tais referências pode auxiliar na formação da identidade dos cursos de Biblioteconomia, na identificação do seu nível de atualização, bem como do seu grau de inserção em relação à literatura produzida nacional e internacionalmente.
Além disso, a nova Lei de Diretrizes e Bases da Educação (LDB) atribuiu às instituições de ensino a responsabilidade de estabelecer seus rumos, buscando conquistar "[...] progressivos graus de autonomia pedagógica e administrativa" (BRASIL, 1996, art.15). Para tal, o Curso de Biblioteconomia da Universidade Federal do Rio Grande do Sul (UFRGS) vem refletindo sobre seus fundamentos filosóficos e epistemológicos, em busca da construção de um Projeto Político Pedagógico (PPP), que aponte para a inovação da prática educacional, dando ênfase para o estudo do currículo como um dos elementos que concretize as concepções defendidas.

O estudo procurou, então, contribuir para esta proposta ao mapear as características das referências utilizadas nos planos de ensino do currículo do curso de Biblioteconomia da UFRGS, sendo este seu objetivo principal. Como objetivos específicos apresentou: verificar os tipos de documentos referenciados; identificar o idioma mais referenciado e a procedência dos autores; verificar os autores mais referenciados; analisar a auto-referenciação e a temporalidade dos documentos indicados; verificar os periódicos mais citados, a distribuição das referências por disciplina e a acessibilidade, na Biblioteca Setorial da Faculdade de Biblioteconomia e Comunicação da UFRGS, dos documentos impressos referenciados; bem como, verificar a disponibilidade, em texto completo, nas bases de dados, dos documentos eletrônicos.

\section{P A NORAMA D A \\ BIBLIOTECONOMIA NOBRASIL}

A formação bibliotecária em nível universitário no Brasil dá-se pela modalidade de bacharelado. Segundo Valentim e Guimarães (2002), são 32 escolas de Biblioteconomia, distribuídas por 19 estados, com diferentes estruturas, englobando 25 instituições de ensino público e 7 de ensino privado. Nas últimas décadas, os cursos sofreram profundas 
modificações, sendo que algumas escolas tradicionais até mesmo encerraram suas atividades. Por outro lado, existem projetos para a formação de novos cursos, com ênfases diferenciadas em licenciaturas, gestão da informação, entre outros.

No Brasil, a partir da nova LDB (BRASIL..., 1996), desencadeou-se o processo para definição das diretrizes curriculares dos Cursos de Biblioteconomia. Nesta perspectiva, a Associação Brasileira de Ensino de Biblioteconomia e Documentação (ABEBD) encaminhou uma proposta de integração dos currículos dos cursos de Biblioteconomia do Mercosul à Secretaria de Estudos Superiores do Ministério de Educação e Cultura (MEC/SESu), incorporando-a ao Parecer 492/2001 do Conselho Nacional de Educação (CNE/CES), aprovado em $3 / 4 / 2001$. Este parecer traça o perfil do egresso do curso e apresenta as competências e habilidades gerais e específicas que o graduado deve apresentar.

Educar é um processo de humanização, pois permite que o indivíduo valorize suas potencialidades. O saber surge como uma construção coletiva, de diálogo e de interação entre sujeitos. Para Azambuja (2004, p.52): "Educar não é domesticar, treinar ou doutrinar, mas reconhecer o outro como dotado de capacidades reflexivas, de auto determinação, de interesses variados [...]". A combinação entre o saber adquirido e a capacidade para produzir conhecimento vão caracterizar a ação educativa e auxiliar a formação de indivíduos autônomos, na medida em que permite o questionamento e alimenta o processo reflexivo. Ensinar é, portanto: "[...] uma atitude que enriquece quem a pratica e quem a recebe. Abre novas perspectivas, inquietações e desafios. Cuida de interpretar melhor a vivência despertando novos encantamentos, [...] leva a aprender".

Novos paradigmas, como interdisciplinaridade, pesquisa em sala de aula, conteúdos significativos e contextualizados, habilidades e competências, vêm permeando as teorias pedagógicas nos últimos tempos, indicando um perfil de aluno que precisa aprender a ser, aprender a conhecer, aprender a fazer e a aprender a conviver. Pensadores como Perrenoud (1999), ao colocar que a educação tem a responsabilidade de preparar pessoas competentes para agir eficazmente no contexto contemporâneo e Paulo Freire que, no Brasil tornou-se, há muito, um ponto de referência para a prática da pedagogia da autonomia, são os fios condutores para a educação do século XXI.

Morin (2002) afirma que o conhecimento não é o espelho do mundo externo, sendo necessários sete saberes à educação do futuro: identificação dos erros da razão, as cegueiras paradigmáticas; conhecimento pertinente ao contexto; educação centrada na condição humana; identidade terrena, que pressupõe aprender a estar no planeta; enfrentamento das incertezas, pela imprevisibilidade do futuro; consciência de ser solidário com a vida e a morte; e a ética, como consciência da cidadania planetária.

Todos esses movimentos estão se tornando um pouco mais visíveis nas salas de aula. A explosão e o intercâmbio da informação, por meio do acesso à Internet, fazem com que haja globalização da cultura, onde todos são cidadãos do mundo. É preciso, como cita Perrenoud (1999), ser competente para agir nesse contexto.

Formar para a competência significa, então, entre outros parâmetros, formar pessoas que saibam se relacionar socialmente, que sejam cidadãos e profissionais competentes, que argumentem com fundamentação e, principalmente, tenham espírito de pesquisa e busca. Na concepção de Davis e Grosbaum (2002, p.70): "[...] ser competente significa ser eficaz na busca de soluções para os problemas fora da rotina do dia-a-dia, agindo com valores éticos e morais, em um clima de boa convivência."

Nesse processo de reflexão, para que a Universidade forme cidadãos críticos e participativos deve procurar organizar seu trabalho pedagógico numa perspectiva democrática, por meio de discussão ativa em relação à construção do seu PPP que, além de ser uma exigência da LDB (BRASIL, 1996), constitui-se no documento maior das instituição de ensino, congregando, em torno de si, os planos, as propostas de ação e demais documentos pertinentes a cada realidade escolar. Construir um projeto pedagógico significa, portanto, enfrentar o desafio da mudança e da transformação, tanto na forma como a escola organiza seu trabalho pedagógico, como na gestão, repensando a estrutura de poder.

Quanto ao currículo, pode ser definido como o "[...] projeto seletivo cultural, social, política e administrativamente condicionado, que recheia a atividade escolar, e que se faz realidade dentro das condições da escola tal como ela se encontra 
configurada." (SANTOS, 2004, p.24). Deve ser abrangente, dinâmico, vivo. É o interagir de tudo e de todos que interferem no processo educacional e não deve se limitar à estruturação das matérias de ensino, mas sim, ir além, aproveitando todas as experiências que promovem e ativam o processo educativo. Deve representar uma seqüência de conhecimentos que formam habilidades para a vida presente e princípios e diretrizes para a vida futura; ao evidenciar a interdisciplinariedade, integração e correlação de tudo o que foi ensinado na escola com a aplicação na prática (MENEGOLLA; SANT'ANNA, 2002).

Já os Planos de Ensino são propostas do professor para execução das suas atividades, atendendo aos princípios legais e a autonomia da instituição. Situam-se num nível bem mais específico e concreto em relação aos demais planos e, de acordo com Menegolla e Sant'Anna (2002, p.68): "[...] são os meios para dinamizar a educação e o ensino. Numa realidade escolar bem concreta, através do processo de ensino [...], compreendem os planos de disciplinas, de unidades, de aulas e de outras atividades ou experiências de ensino." Este entendimento, no entanto, não é suficientemente repassado aos docentes, que atuam com planejamentos repetitivos, ano após ano, embora recebendo novos alunos a cada período letivo.

O plano de ensino pode ser somente uma imposição burocrática semestral, cujo trâmite inicia no Departamento de um curso e acaba em algum arquivo ou pasta. Para o professor, que pouco retorno recebe sobre o plano, pode ser apenas mais um formulário a ser preenchido. Entretanto, a idéia básica deste documento é de que seja uma sistematização do ensino, para que se obtenha melhor aprendizagem. Para Moreira (1983, p.13), pode-se apontar como objetivo principal do plano:

[...] sua utilização como sistema de referência para o trabalho do aluno e do professor ao longo do curso. Ele dá uma idéia da direção às várias atividades durante o curso. É um guia ou roteiro de ação que evita o desenvolvimento casual ou caótico do processo ensinoaprendizagem.

Para cumprir tais objetivos, o plano deve atender ao critério de flexibilidade, adaptando-se às mudanças necessárias, tanto do ambiente externo, como as transformações culturais e sociais, quanto à evolução do conhecimento.
São componentes básicos de um plano de ensino: dados de identificação; súmula da disciplina; objetivos; conteúdo programático; estratégias de ensino; sistema de avaliação; e referências. Nele estão contidas orientações ao trabalho do professor, sua metodologia, e referências que irão fundamentar a teorização que vai abarcar em aula.

Para fundamentar a teorização, o professor indica os referenciais do plano de ensino, oferecendo aos alunos informações que lhes proporcionem subsídios para analisar, compreender, aplicar e reconstruir as situações na vida real (HENGEMÜHLE, 2004). Esta pode ser uma importante contribuição para que o aluno assuma uma posição investigativa, de pesquisa, de construção do conhecimento além da sala-de-aula. O professor, ao indicar referências nos planos de ensino, oferece fontes de pesquisa, de direções para complementar a formação, de tal modo que não restrinja os estudos ao que é repassado unicamente no ambiente formal de aprendizagem.

\section{MÉTODOS}

Trata-se de um estudo bibliométrico, que utilizou a técnica de Análise de Referências. Partindo de uma abordagem quantitativa, foram exploradas as possibilidades de análise e interpretação dos resultados obtidos. Os objetos do estudo foram constituídos pelos planos de ensino das 29 disciplinas obrigatórias e ministradas pelo Departamento de Ciências da Informação (DCI) do curso de Biblioteconomia da UFRGS, constantes do currículo do primeiro semestre de 2004. As unidades de análise foram as referências contidas nos planos de ensino. Exclui-se do estudo as disciplinas "Estágio Curricular Obrigatório", "Introdução ao Trabalho de Conclusão" e "Trabalho de Conclusão de Curso", uma vez que não apresentam referências. Esta documentação encontra-se arquivada e disponível para consulta na Secretaria do (DCl) da Faculdade. Não foram consideradas também neste trabalho as disciplinas eletivas e as obrigatórias não específicas do Departamento.

Por ser dinâmico, o currículo sofre ajustes e modificações periódicas em virtude da evolução do conhecimento. Assim, para analisar as referências indicadas nos planos de ensino foi preciso imobilizá-lo, efetuando um corte temporal, a fim de que se 
pudesse traçar um perfil do momento. O período selecionado, o primeiro semestre de 2004, apresentou a contextualização no tempo estudado, sem se ater ao antes e ao depois.

As fontes principais da pesquisa foram: o arquivo do DCI da UFRGS; a Biblioteca Setorial de Biblioteconomia e Comunicação da UFRGS, onde foi verificada a disponibilidade dos documentos impressos; o Portal de Periódicos da Coordenação de Aperfeiçoamento de Pessoal de Nível Superior (Capes), para verificar a acessi-bilidade dos artigos em meio eletrônico; o Currículo Lattes e buscadores da Internet, para localizar a procedência dos autores.

Foram utilizadas planilhas eletrônicas para o registro dos dados, utilizando-se o programa MSEXCEL ${ }^{\circledR}$. Os dados quantitativos foram tratados em percentuais e médias, e analisados com base no referencial teórico, através do confronto entre os objetivos, pesquisa e as particularidades da situação.

\section{RESULTADOSE DISCUSSÃO}

O estudo coletou 420 referências, distribuídas em 29 disciplinas obrigatórias e ministradas pelo $\mathrm{DCl}$, no primeiro semestre de 2004 (Tabela 1).

O número médio de referências foi 14,48 sendo a disciplina com maior número "Metodologia da PesquisaAplicada às Ciências da Informação" com 39 citações, seguida de "Estudo de Comunidades e Usuários", com 34 referências. Ambas são disciplinas com fortes características de pesquisa, que exigem envolvimento e comprometimento dos alunos em

Tabela 1. Distribuição das referências por disciplina.

\begin{tabular}{|c|c|c|c|}
\hline \multirow[b]{2}{*}{ Disciplinas } & \multicolumn{3}{|c|}{ Referências } \\
\hline & $\mathrm{n}$ & $\%$ & $\%$ acumulada \\
\hline BIB03072 - Serviços de Informação e Atendimento à Comunidade & 1 & 0,25 & 0,25 \\
\hline BIB03017 - Gestão de Recursos em Sistemas de Informação & 2 & 0,47 & 0,72 \\
\hline BIB03061 - Representação DescritivaA & 2 & 0,48 & 1,20 \\
\hline BIB03063 - Representação Descritiva C & 3 & 0,71 & 1,91 \\
\hline BIB03031 - Marketing em Sistemas de Informação & 6 & 1,44 & 3,35 \\
\hline BIB03010 - Administração Aplicada às Ciências da Informação & 6 & 1,50 & 4,85 \\
\hline BIB03027 - Gestão de Serviços Informacionais & 7 & 1,66 & 6,51 \\
\hline BIB03033 - Gerência e Consultoria de Sistemas de Informação & 7 & 1,66 & 8,17 \\
\hline BIB03062 - Representação Descritiva B & 8 & 1,90 & 10,07 \\
\hline BIB03078 - Fundamentos das Ciências da Informação & 9 & 2,14 & 12,21 \\
\hline BIB03018 - Linguagem de Indexação II & 9 & 2,14 & 14,35 \\
\hline BIB03028 - Planejamento d Elaboração de Bases de Dados & 9 & 2,14 & 16,49 \\
\hline BIB03016 - Fontes Gerais de Informação & 13 & 3,09 & 19,58 \\
\hline BIB03030 - Planejamento de Sistemas de Informação & 13 & 3,09 & 22,67 \\
\hline BIB03013 - Linguagem de Indexação I & 14 & 3,33 & 26,00 \\
\hline BIB03076 - História dos Registros Humanos & 15 & 3,57 & 29,57 \\
\hline BIB03022 - Gestão de Recursos Informacionais & 16 & 3,80 & 33,37 \\
\hline BIB03064 - Produção de Documentos Eletrônicos & 16 & 3,80 & 37,17 \\
\hline BIB03005 - Fundamentos Organizacionais e Tratamento da Informação & 17 & 4,04 & 41,21 \\
\hline BIB03077 - Introdução às Ciências da Informação & 18 & 4,28 & 45,49 \\
\hline BIB03008 - Introdução à Representação Temática & 18 & 4,28 & 49,77 \\
\hline BIB03032 - Produtos de Recuperação da Informação & 19 & 4,52 & 54,29 \\
\hline BIB03023 - Pesquisa e Desenvolvimento de Coleções & 19 & 4,54 & 58,83 \\
\hline BIB03011 - Geração de Documentos & 21 & 5,00 & 63,83 \\
\hline BIB03079 - Informação Especializada & 21 & 5,00 & 68,83 \\
\hline BIB03015 - Indústria da Informação e do Conhecimento & 28 & 6,66 & 75,49 \\
\hline BIB03024 - Linguagens Alfabéticas de Indexação & 30 & 7,14 & 82,63 \\
\hline BIB03021 - Estudo de Comunidades e Usuários & 34 & 8,09 & 90,72 \\
\hline BIB03060 - Metodologia da Pesquisa Aplicada às Ciências da Informação & 39 & 9,28 & 100,00 \\
\hline Total Geral & 420 & 100 & \\
\hline
\end{tabular}


busca de referenciais teóricos. Percebe-se a intenção dos professores em indicar caminhos para que os alunos construam conhecimento e competências, orientados, porém com autono-mia, como é a tendência da educação moderna, do aprender a aprender (PERRENOUD, 1999; DEMO, 2000).

Outras disciplinas como "Serviços de Informação e Atendimento à Comunidade" e "Gestão de Recursos em Sistemas de Informa-ção", apresentaram baixo número de referências nos planos. Tal ocorrência pode significar (sendo inclusive citado em alguns planos de ensino) que os professores indicaram documentos para consulta no decorrer do semestre.

Outra observação que pode ser feita em relação aos dados apresentados é de que a média do número de referências $(14,48)$ coincide com a metade do número de disciplinas. No entanto, 11 das 29 disciplinas respondem por $60 \%$ do total de referências.

Estudo da Capes (1978) sobre a literatura dos cursos de Biblioteconomia brasileiros concluiu, com base no número de referências dos planos de ensino, que havia orientação excessiva para as disciplinas técnicas. Catalogação apresentou, na época, o maior percentual de referências (16,64\%), enquanto que Planejamento Bibliotecário, considerado naquela pesquisa como envolvendo uma base mais interdisciplinar por incluir questões sociais e políticas, teve apenas $0,38 \%$. Na comparação daqueles resultados com este estudo, houve mudança do quadro, principalmente pela inclusão no currículo de disciplinas com base humanística.

Vale ressaltar o que foi apontado por Dias, Pitello e Pontello (1996) sobre a carência de textos de natureza didática em língua portuguesa, em pesquisa realizada sobre a literatura do ensino de graduação em Biblioteconomia no Brasil, o que faz com que muitos professores busquem outras alternativas e recursos que vão além da sala-de-aula, como visitas a instituições, por exemplo, unindo a teoria à prática.

Em relação à tipologia, dos 420 documentos referenciados, as 35 referências a "outros" tipos merecem ser esmiuçadas, pois abarcam 17 normas da Associação Brasileira de Normas Técnicas (ABNT), 7 páginas da Internet, 7 leis, 3 artigos não científicos de páginas na Internet e 1 filme de videocassete (Tabela 2).
Tabela 2. Tipo de documento.

\begin{tabular}{lc}
\hline Tipo de Documento & Referências \\
\hline Livro & 212 \\
Artigo de periódico nacional & 91 \\
Capítulo de livro & 36 \\
Artigo de periódico estrangeiro & 20 \\
Apostila & 5 \\
Trabalho apresentado em evento nacional & 3 \\
Periódico no todo & 3 \\
Trabalho apresentado em evento internacional & 2 \\
Teses e dissertações & 2 \\
Evento nacional no todo & 1 \\
Outros & 35 \\
\hline Total & 420 \\
\hline
\end{tabular}

Livro e capítulo de livro perfazem $60 \%$ das citações, confirmando a preferência deste tipo de documento pelas Ciências Sociais, incluindo aí as Ciências Sociais Aplicadas e a Biblioteconomia, cujo aspecto discursivo é mais compatível com o formato amplo de um livro do que de um artigo, conforme Figueiredo (1990). A autora ainda cita que estas ciências têm um desenvolvimento relativamente moroso e não produzem descobertas a serem divulgadas imediatamente, o que justifica o uso de fontes de informação com valor mais duradouro, enquanto que os artigos podem ser efêmeros.

No entanto, o estudo realizado pela Capes (1978, p.6) já indicava preocupação quanto à excessiva ênfase dada ao livro como fonte de informação e como material didático, aparecendo simplesmente como substituto à apostila. A análise dos dados demonstrava a preocupação dos autores quanto a:

[...] necessidade de colocar ao alcance do aluno/leitor e de reforçar o valor da informação, independentemente de sua forma e encontrar mecanismos que possibilitem motivar um uso mais freqüente de fontes alternativas, entre elas, as coleções hemerográficas, como para justificar o investimento e fazer maior uso de sua potencialidade informacional.

Isto parece ter levado a própria Capes a proporcionar ao ensino de graduação e de pós-graduação mecanismos para utilização de artigos de periódicos, que resultaram, entre outros produtos, do Portal de Periódicos da Capes, uma fonte inestimável à pesquisa, ao proporcionar o acesso a 
artigos eletrônicos com texto completo, de periódicos nacionais e internacionais, em todas as áreas do conhecimento científico, sendo artigos de periódicos científicos o principal canal de divulgação da ciência (STUMPF, 1994; MEADOWS, 1999). Neste estudo, 121 artigos foram referenciados, correspondendo a $39 \%$ do total. Destes, 91 foram publicados em periódicos nacionais e 20 em estrangeiros, o que evidencia tendência à mudança de comportamento dos pesquisadores da área e o enfoque interdisciplinar da Ciência da Informação, valendo-se para isso de instrumentais até então pertencentes às ciências ditas "duras" (MEADOWS, 1999).

Quanto ao número expressivo de artigos de autores brasileiros em periódicos nacionais (91), evidencia-se o aumento da produção dos pesquisadores, que estão publicando cada vez mais neste canal de divulgação da ciência. Estudo da Capes (1978) revelava preocupação com ausência de conjunto de textos básicos nacionais para organizar e apresentar os conhecimentos de origem variada, fazendo com que os professores utilizassem autores estrangeiros traduzidos, muitas vezes fora do contexto local. Deve-se elogiar, então, o esforço dos autores brasileiros, que mesmo em condições nem sempre adequadas, estão contribuindo para aumentar a visibilidade do país neste campo.

Por fim, pode-se citar que a ciência, em qualquer dimensão, somente se materializa na produção de documentos de todos os tipos. Segundo Santos (2003, p.34):

Quando pesquisadores elaboram pesquisas, eles produzem artigos; quando participam de processo de inovação, depositam patentes [...]; quando se envolvem com docência, dirigem tese, elaboram manuais, apostilas; quando participam de programas públicos, redigem projetos [...] e relatórios [...] e, se consagram à popularização, elaboram livros, roteiros, contribuem para a redação de regulamentos, de pareceres [...] Considerada, nas cinco dimensões expostas, a pesquisa é uma vasta empresa de escritura: prolifera documentos de todos os tipos.

O estudo da Capes (1978) ressalta que a Biblioteconomia deve agregar todos esses recursos. Apenas 20\% dos documentos pertencem a outras categorias além de livros e artigos. As publicações de trabalhos apresentados em eventos nacionais e internacionais, por exemplo, apesar de serem fonte importante por refletir o panorama da área e o perfil dos seus membros (CAMPELLO; CENDÓN; KREMER, 2000), correspondem a menos de 1\% das referências. Teses e dissertações, documentos originados dos programas de pós-graduação, receberam apenas uma citação.

Por outro lado, algumas disciplinas estão se valendo de páginas e textos eletrônicos da Internet, o que pode ser explicado pela necessidade de formar profissionais adaptados ao mercado, que saibam reconhecer e buscar a informação em qualquer formato. Segundo Ohira et al. (2002, p.75):

[...] estamos vivenciando uma fase de mudanças significativas em todos os aspectos da sociedade. Os perfis dos profissionais estão em constante processo de mudança, em função das tecnologias emergentes. Valores e paradigmas estão sendo quebrados a uma velocidade cada vez maior. A mudança do paradigma do acervo para a informação força o bibliotecário a desviar sua atenção do meio físico (documento) para seu objeto (a informação).

Esta mudança de paradigma deve ser considerada uma evolução, concretizada por meio de visão gerencial, poder de análise, criatividade e constante atualização dos seus profissionais.

Quanto ao formato dos documentos, apresenta-se em três categorias: impressos (328 referências), eletrônicos (44) e os tanto no formato eletrônico como impresso (48). Para este último, verificou-se a existência da obra no formato impresso, no catálogo da Biblioteca, e o acesso ao texto completo em fontes eletrônicas.

Livro é o tipo de documento predominante no formato impresso, enquanto que artigos aparecem nas três formas. Dos 121 artigos citados, 68 são impressos, 24 são eletrônicos e 29 apresentam-se nos dois formatos: impresso e eletrônico, principalmente devido ao periódico Ciência da Informação, que desde 1995 disponibiliza artigos na Internet, mas continua mantendo o formato tradicional impresso. Como é o periódico mais citado nos planos de ensino, os dados ficam consolidados.

Para efeitos deste trabalho, foram considerados autores citados tanto pessoais como institucionais. Nas referências com mais de três autores, foi contado o que aparece em primeiro lugar. 
Quanto à procedência dos autores, do total de 330 referenciados, 197 são de instituições nacionais (60\%) e 133 de outros países. O resultado segue a tendência de estudo anterior (DIAS; PITELLO; PONTELLO, 1996), que apontou $67,2 \%$ de literatura nacional nos planos de ensino de dois cursos de graduação em Biblioteconomia no Brasil, demonstrando que tanto autores nacionais como estrangeiros são utilizados, mas a maioria é vinculada a insti-tuições brasileiras.

De acordo com os dados, a Universidade de Minas Gerais (UFMG) é a instituição cujos autores são mais citados, com 13,0\%. Segue a Universidade de Brasília (UnB) com 11,0\%, UFRGS (10,0\%), Universidade de São Paulo (USP) (7,5\%), Instituto Brasileiro de Informação em Ciência e Tecnologia (IBICT) (7,0\%), Universidade Federal Fluminense (UFF) (5,0\%), e Universidade Federal de Santa Catarina (UFSC), Universidade Estadual Paulista (UNESP), PUCRS, Universidade Federal do Rio de Janeiro (UFRJ), Pontifícia Universidade Católica de São Paulo (PUC-SP), Universidade do Vale do Itajaí (Univali) e Universidade Estadual de Campinas (Unicamp) com menos de 5,0\% cada. Estas instituições detêm mais de $70,0 \%$, dispersando-se o restante entre as que foram citadas anteriormente. Percebe-se forte presença de universidades, principalmente as que oferecem cursos na área. Houve também a presença de instituições cuja principal atividade não é o ensino, sendo o IBICT o maior exemplo, com 9 referências, o que mostra a importância deste instituto e o seu vigor produtivo para a pesquisa na área.

Houve a ocorrência de 37 autores não ligados a instituições acadêmicas ou de pesquisa, como consultores, bibliotecários que atuam em empresas privadas, escritores de sucesso, entre outros, a maioria citada nas disciplinas ligadas à área de administração. Pode-se deduzir que esta área utiliza autores direcionados às necessidades de mercado. Os professores das disciplinas precisam repassar, então, não apenas o conhecimento produzido por teóricos da área, mas pelos que estudam e acompanham a tendência local e mundial, para formarem profissionais dinâmicos e competitivos, que atendam aos anseios da sociedade (OHIRA et al., 2002).

Os autores estrangeiros foram analisados quanto ao país de procedência, verificada em busca à Internet ou na própria obra, sendo os norte-americanos os de maior número, com $36,8 \%$ das referên- cias, seguidos dos ingleses com $20,0 \%$, franceses $(15,0 \%)$, e espanhóis $(9,0 \%)$. Tais resultados evidenciam a influência da literatura destes países na formação dos profissionais da área. Os dados também demonstram que os autores considerados clássicos - utilizando uma noção qualitativa -, são aqueles reconhecidos pela comunidade científica, expressos tanto nas citações como na comunicação informal e em sala de aula (VANZ, 2004) - são freqüentemente ingleses e franceses. Artigos de periódicos da área da informação propriamente dita ocorreram mais entre ingleses, franceses e espanhóis. Autores americanos apresentam obras principalmente no formato livro, com assuntos pertencentes às áreas de administração (9 referências), informática (5), desenvolvimento de coleções (4), futuro do livro (3), entre outros.

Em relação à autocitação, McRoberts e McRoberts (1989) comentam que os autores são mais inclinados a citar seu próprio trabalho do que os dos outros. No entanto, somente uma cuidadosa análise do texto pode dizer se as autocitações foram importantes ou supérfluas. Observou-se o fenômeno de autocitação neste estudo, no qual quatro professoras referenciaram suas obras, o que evidencia o envolvimento destas com a continuidade das pesquisas na área, além do aproveitamento didático dessa produção.

A pesquisa ainda indicou predomínio absoluto de referências a autoria pessoal, com $86 \%$. Os 14\% relativos à autoria institucional dizem respeito, principalmente, às normas daABNT (17); Legislação Brasileira (7 leis); e IBICT, responsável por várias obras utilizadas no curso. Em torno de $70 \%$ dos documentos foram de autoria única, reforçando a idéia de que as Ciências Sociais e Humanidades, aqui incluída para efeitos de análise, a Ciência da Informação e a Biblioteconomia não costumam publicar em cooperação (MEADOWS, 1999). Das referências, 24\% foram de múltipla autoria, e 14 sem autoria (5\%). Este percentual, apesar de pouco expressivo em relação ao total, explica-se pelas páginas da Internet. Por outro lado, não foi verificada apresentação errada de referências, que comprometesse a identificação do documento.

Os resultados evidenciaram a inexistência de um grupo de autores fortemente citados, já que 65\% das citações concentraram-se em escritores referenciados apenas uma vez. Isto já era de se esperar, 
uma vez que as disciplinas, por apresentarem objetivos diferentes, utilizam autores diversos. Também expõe a ampla gama de teóricos existentes na área. $\mathrm{O}$ autor pessoal mais citado foi Frederick Lancaster, com nove referências a quatro obras diferentes. É um autor consagrado e considerado clássico, sendo largamente utilizado no curso de Biblioteconomia. Nice Figueiredo, pesquisadora do IBICT e autora de livros e artigos, teve oito referências nos planos. Já os franceses Guinchat e Menou tiveram o livro Introdução Geral às Ciências e Técnicas da Informação e Documentação citado por oito disciplinas. É uma obra introdutória ao curso e à Ciência da Informação, muito utilizada no ensino de graduação.

Bernadete Campello, da UFMG, foi outra autora muito citada, com cinco referências. Organizou os livros Fontes de Informação para Pesquisadores e Profissionais, em co-autoria com Carlita Campos e Jeanette Kremer (referenciado por cinco professores); Fontes de Informação Especializada, em co-autoria com Beatriz Céndón; Formas e Expressões do Conhecimento, com Paulo da Terra Caldeira e Vera A. Amarante Macedo. Também é autora, com Maria Helena de Andrade Magalhães, da obra Introdução ao Controle Bibliográfico. Muitas disciplinas referenciaram capítulos desses livros, o que confirma a relevância do conjunto da produção.

Autores nacionais como Alice Príncipe Barbosa e Astério Campos, clássicos da literatura técnica, apareceram cinco vezes. Antônio Miranda, Alba Costa Maciel, Valdomiro Vergueiro, Aldo Barreto, Maria Augusta Cesarino, Maria Cristina B. F. Pinto e Sueli Ferreira tiveram quatro referências. Outros autores, com três referências, foram Le Coadic, Eliane Mey e Emília Currás, Foskett e Chiavenato (administração). Embora citado em apenas uma disciplina, com cinco obras, é louvável a presença de um autor como Edgar Morin, inter, multi e transdisciplinar, com mais de 30 livros considerados clássicos contemporâneos.

Quanto à temporalidade dos documentos, a maior parte foi publicada depois de 1990, com quase $70 \%$, o que sugere contemporaneidade. À medida que se regride no tempo, menor é a quantidade de obras referenciadas. Entretanto, como o tipo de documento mais citado foram livros, pode-se supor que as datas recentes indicam reedição ou reimpressão atualizada da obra, sendo tais resultados apontados também em trabalhos anteriores (DIAS;
PITELLO; PONTELLO, 1996; VANZ, 2004). Justifica-se a contemporaneidade pela própria evolução do conhecimento, pois o currículo do curso de Biblioteconomia, sob o enfoque da Ciência da Informação, possui disciplinas interdisciplinares que exigem competências ligadas às tecnologias da informação, com referenciais teóricos recentes.

Em relação ao idioma, predominou o português, com $83 \%$, seguido do inglês( $9 \%)$ e espanhol (8\%). Com base nas limitações dos alunos de graduação em outros idiomas, são justificáveis os resultados. O baixo percentual em inglês deve-se aos livros traduzidos e editados no Brasil. Conforme estudo da Capes (1978), sobre a literatura utilizada nos cursos de Biblioteconomia no país, é de estranhar o percentual para referências em espanhol, já que este é o idioma oficial de organismos internacionais como a Organização das Nações Unidas para a Educação, a Ciência e a Cultura (Unesco) e por ser acessível aos brasileiros.

A análise dos periódicos revelou 121 referências a 30 títulos, nacionais e estrangeiros, no formato impresso, eletrônico e impresso e eletrônico. Verificou-se a importância do periódico "Ciência da Informação" para a área. Dos 29 planos de ensino, 11 o referenciaram, num total de 27 citações, o que reafirma a qualidade dos artigos publicados, além da variedade dos assuntos que cobre, atendendo a disciplinas de áreas distintas do currículo. Merece destaque o IBICT que, ao editar este periódico, em formato impresso e eletrônico, possibilita consulta em texto completo também àqueles que tenham acesso à Internet. O segundo mais citado foi Perspectivas em Ciência da Informação, da UFMG, impresso, semestral, com sumários na Internet. Outros periódicos impressos citados foram Revista de Biblioteconomia de Brasília, da Associação de Bibliotecários do Distrito Federal, paralisado diversas vezes desde seu lançamento, em 1973; e Transinformação, do Departamento de Pós-Graduação em Biblioteconomia e Ciência da Informação da Pontifícia Universidade Católica de Campinas, quadrimestral. Entre os periódicos eletrônicos foram citados o DataGramaZero, com acesso e texto integral na Internet e Informação \& Sociedade: Estudos, da Universidade Federal da Paraíba, disponibilizado nos dois formatos.

Outro item estudado foi a disponibilidade e acesso dos documentos. Das 376 referências a docu- 
mentos impressos e impressos/eletrônicos, a Biblioteca Setorial da Faculdade possui no acervo 326 obras, correspondendo a 86,7\%, percentual razoável, tendo em vista a situação precária em que se encontram as universidades públicas no país. Mesmo com recursos escassos, a Biblioteca consegue manter um nível adequado de atendimento às necessidades informacionais dos usuários, embora não atenda $14 \%$ do que o professor indica como literatura básica nos planos.

Quanto ao acesso ao texto eletrônico de documentos na Internet, a Biblioteca conta, principalmente, com o Portal de Periódicos da Capes, com mais de 8 mil títulos de periódicos. Foram referenciados 39 artigos eletrônicos, cujos textos estão disponíveis no Portal, número insuficiente, considerando que a maioria pertence a um periódico: Ciência da Informação. Poucos títulos estrangeiros foram referenciados, o que pressupõe utilização insuficiente da fonte. No entanto, sabe-se das restrições dos alunos de graduação quanto a línguas estrangeiras, o que dificulta a utilização do recurso.

\section{CONSIDERAÇÕ ES FINAIS}

A análise das referências dos planos de ensino das disciplinas obrigatórias oferecidas pelo Departamento de Ciências da Informação para o Curso de Biblioteconomia da UFRGS evidenciou alguns aspectos para reflexão. Entre eles, o número de referências por disciplina mostrou uma distribuição simétrica em torno da média (14 disciplinas situavam-se acima da média de 14,48 referências e 15 disciplinas abaixo disto). O estudo revelou também que 11 disciplinas representaram $60 \%$ do total de referências. Mesmo assim pôde-se notar que algumas apresentaram um número de referências muito baixo, indicando que o plano de ensino precisa ser complementado com indicações de leitura ao longo do semestre.

Pode-se considerar ainda que, em comparação com pesquisas anteriores, houve crescimento da referenciação a obras nacionais, dado o número de autores brasileiros citados. Este é um resultado positivo, pois os autores, ao escreverem livros e artigos, estão contribuindo para formar um patrimônio intelectual bibliotecário do Brasil. É possível afirmar que há um conjunto de autores e instituições nacionais, principalmente nos cursos de pós-graduação, produzindo obras importantes para a criação de uma base teórica e sistematizando conhecimentos. No entanto, ainda há muitos desafios a enfrentar. É preciso incrementar investimentos em pesquisa na área, além de, principalmente, fazer da escola de Biblioteconomia uma instituição pesquisadora.

Neste sentido, para evitar um ensino meramente reprodutor, deve haver comprometimento maior de todo o corpo docente com a criação do conhecimento na área. A maturidade científica do professor tem reflexos positivos no desenvolvimento do aluno e, se cabe à instituição propiciar condições para a capacitação docente, a contrapartida exige o compromisso com a produção e divulgação do conhecimento. A sala de aula deve ser um espaço de diálogos e práticas que conduzam os discentes ao pensamento consciente e crítico. O professor que pesquisa traz com ele uma concepção de ensino questionador, de orientador do aluno no processo de construção e reconstrução do saber.

Em relação ao idioma mais citado, o português (83\%), seria utópico esperar outro resultado. O professor, em geral, hesita em referenciar obras estrangeiras, pela pouca familiaridade do aluno com outras línguas. Estes dados refletem a identidade do aluno de graduação, que vem pouco preparado para a universidade, em virtude da formação média deficiente.

Outro ponto que merece reflexão é o da disponibilidade e acesso dos documentos referenciados junto a Biblioteca. Verificou-se $86 \%$ de resposta positiva, em relação às referências de documentos impressos. Analisando isoladamente, parece um bom percentual. No entanto, não se trata de estatística de atendimento e sim da acessibilidade das obras solicitadas pelos professores. Isto significa que a Biblioteca não atendeu a 14\% daquilo que os professores referenciaram nos planos. Esse fato traz implícita uma questão cuja resposta a maioria dos alunos conhece: o professor, seguidamente, disponibiliza suas obras ou deixa textos em "pastas", para cópia. Por outro lado, pode existir um processo de acomodação, onde o professor, pela falta de recursos próprios para a aquisição pessoal de material atualizado, cita somente o que a Biblioteca tem. A Biblioteca, também devido à falta de recursos financeiros, não atualiza freqüentemente sua coleção, 
fazendo com que seus usuários, alunos e docentes, utilizem material pouco atual.

É importante ressaltar que os dados referem-se a um período de seis meses e expressam a realidade do momento, podendo se alterar nos próximos períodos. O estudo teve enfoque quantitativo, porém ficou evidenciado um quadro que merece reflexão. Seria recomendável, para complementar, que se verificassem as razões de citação, ou seja, que motivos levaram os professores a citar as referências nos planos. Outra questão diz respeito à utilidade dos planos de ensino. Não é possível afirmar se sua elaboração é apenas uma exigência legal ou se realmente servem de guia e orientação aos alunos. Este deveria ser o objetivo principal dos planos: uma fonte referencial para pesquisas e para educação continuada.

Por fim, buscou-se contribuir para a formação da identidade e o autoconhecimento do curso de Biblioteconomia da UFRGS. Não pretendeu ser um trabalho exaustivo, pois teve como preocupação básica fornecer dados sobre a literatura utilizada na formação dos futuros profissionais da informação, através de alguns aspectos dos documentos referenciados nos planos de ensino.

\section{REFERÊNCIAS}

ASSOCIAÇÃO BRASILEIRADE EDUCAÇÃO EM CIÊNCIADA INFORMAÇÃO. Avaliação da graduação em Biblioteconomia e Ciência da Informação: bases conceituais, metodológicas e princípios do processo avaliativo. Vitória, 2002. (Documentos ABECIN, 2). Disponível em: <http://www.abecin.org/ Documentos abecin.htm>. Acesso em: 6 maio 2004.

AZAMBUJA, M.L.F. A Construção da autonomia intelectual: a universalidade do papel do professor. In: GROLLI, D.; AZAMBUJA, M.L.F.; GAZZOLA, T. O professor, o aluno e a investigação em sala de aula. Porto Alegre: Evangraf, 2004. p.37-56.

COORDENAÇÃO DEAPERFEIÇOAMENTO DE PESSOALDE NÍVEL SUPERIOR. O ensino de Biblioteconomia no Brasil. Brasília: CAPES, 1978. v.3: Análise da literatura recomendada no ensino de Biblioteconomia no Brasil.

BRASIL. Ministério de Educação e Cultura. Lei de Diretrizes e Bases da Educação: Lei 9.394 de 20 dez. 1996. Cachoeira do Sul: GT, 1996.

CAMPELLO, B.S.; CENDÓN, B.V.; KREMER, J.M. Fontes de informação para pesquisadores e profissionais. Belo Horizonte: UFMG, 2000.

DAVIS, C.; GROSBAUM, M.W. Sucesso de todos, compromisso da escola. In: DAVIS, C. et al. (Org.). Gestão da escola: desafios a enfrentar. Rio de Janeiro: DP\&A, 2002. p.77-112.

DEMO, P. Desafios modernos da educação. 10.ed. São Paulo: Vozes, 2000.

DIAS, E.J.W.; PITELLO, M.C.; PONTELLO, A.G.G. Literatura utilizada no ensino de graduação em Biblioteconomia no Brasil: produtividade institucional. Perspectivas em Ciência da Informação, Belo Horizonte, v.1, n.2, p.157-176, 1996.

FIGUEIREDO, N.M. Metodologias para promoção do uso da informação: técnicas aplicadas particularmente em bibliotecas universitárias e especializadas. São Paulo: Nobel, 1990.

HENGEMÜHLE, A. Gestão de ensino e práticas pedagógicas. Petrópolis: Vozes, 2004.

McROBERTS, M.H.; McROBERTS, B.R. Problems of citation analysis: a critical review. Journal of the American Society for Information Science, v.40, n.5, p.342-349, 1989.
MEADOWS, A.J. A comunicação científica. Brasília: Briquet de Lemos, 1999.

MENEGOLLA, M.; SANT'ANNA, L.M. Por que planejar? Como planejar? currículo - área - aula: escola em debate. 12. ed. Petrópolis: Vozes, 2002.

MOREIRA, M.A. Ação docente na universidade: textos relativos a componentes básicos do ensino. Porto Alegre: Ed. da Universidade, 1983. (Texto para discussão, 11).

MORIN, E. Os sete saberes necessários à educação do futuro. 5.ed. São Paulo: Cortez, 2002.

OHIRA, M.L.B. et al. Alteração curricular do curso de Biblioteconomia da Universidade do Estado de Santa Catarina - UDESC. Transinformação, Campinas, v.14, n.1, (Edição especial), p.71-82, 2002.

PERRENOUD, P. Construir as competências desde a escola. Porto Alegre: Artmed, 1999.

SANTOS, R.N.M. Produção científica: por que medir? O que medir? Revista Digital da Biblioteconomia e da Ciência da Informação, Campinas, v.1, n.1, p.22-38, 2003.

SANTOS, V.M.D. Projeto político pedagógico: desafios e conquistas na caminhada. 2004. 183f. Dissertação (Mestrado em Educação) - Programa de Pós-Graduação em Educação. Universidade do Estado de Santa Catarina, Florianópolis, 2004.

STUMPF, I.R.C. Revistas universitárias: projetos inacabados. 1994. 302f. Tese (Doutorado) - Programa de Pós-Graduação em Ciências da Comunicação, Escola de Comunicações e Artes, Universidade de São Paulo, São Paulo, 1994.

VALENTIM, M.L.P.; GUIMARÃES, J.A.C. Diretrizes políticas e estratégicas para a formação docente voltadas à pesquisa e a extensão: Brasil. Transinformação, Campinas, v.14, n.1, p.29-39, 2002.

VANZ, S.A.S. A Produção discente em comunicação: análise das citações das dissertações defendidas nos programas de pós-graduação do Rio Grande do Sul. 2004. 145f. Dissertação (Mestrado) - Programa de Pós-Graduação em Comunicação e Informação, Universidade Federal do Rio Grande do Sul, Porto Alegre, 2004. 
